\title{
Nowcasting Growth Rates of Russia's Export and Import by Commodity Group ${ }^{1}$
}

\author{
Ksenia Mayorova, RANEPA \\ mayorovak99@gmail.com \\ Nikita Fokin, RANEPA \\ fokinikita@gmail.com
}

In this paper, we apply a set of machine learning and econometrics models, namely: Elastic Net, Random Forest, XGBoost, and SSVS to nowcast (estimate for the current period) the dollar volumes of Russian exports and imports by a commodity group. We use lags in the volumes of export and import commodity groups, and exchange prices for some goods and other variables, due to which the curse of dimensionality becomes quite acute. The models we use have proven themselves well in forecasting in the presence of the curse of dimensionality, when the number of model parameters exceeds the number of observations. The best-performing model appears to be the weighted machine learning model, which outperforms the ARIMA benchmark model in nowcasting the volume of both exports and imports. According to the Diebold-Mariano test, in the case of the largest commodity groups our model often manages to obtain significantly more accurate nowcasts relative to the ARIMA model. The resulting estimates turn out to be quite close to the Bank of Russia's historical forecasts built under comparable conditions.

Keywords: nowcasting; foreign trade; curse of dimensionality; machine learning; Russian economy

JEL Codes: C52, C53, C55, F17
Citation: Mayorova, K. and Fokin, N. Nowcasting Growth Rates of Russia's Export and Import by Commodity Group. Russian Journal of Money and Finance, 80(3), pp. 34-48.

doi: $10.31477 /$ rjmf.202103.34

\section{Introduction}

In this paper, we use a large set of quarterly data from the Federal Customs Service (FCS) on the value (i.e. nominal) volumes of exports and imports by

1 The paper has been prepared as part of the research on the state assignment of the Russian Presidential Academy of National Economy and Public Administration (RANEPA). The authors express their gratitude to the two anonymous reviewers for their valuable comments, which have improved this paper. 
commodity group according to the Foreign Economic Activity Commodity Nomenclature (FEACN) classification. ${ }^{2}$ We forecast export and import volumes growth rates for two-digit commodity groups, with the lags of volume growth rates, the real effective rouble exchange rate, prices for some commodities exported from and imported to Russia that are traded on international commodity exchanges (oil, gas, various metals), and other variables used as predictors.

We pursue two objectives. The first one is testing the quality ${ }^{3}$ of nowcasting for the considered models using the dataset of exports and imports by commodity group. The second objective is to compare the quality of the nowcasts of the key indicators (total exports and total imports) built with the help of machine learning models, and the Bank of Russia's quarterly nowcasts.

Forecasting of exports and imports dynamics is an important task. High-quality forecasts of export and import volumes help the government to plan its foreign trade activities better, pursue a more appropriate foreign exchange market policy, e.g. adjust budget rule parameters, and implement an effective trade and customs policy to maintain the competitiveness of domestic producers. It is also worth noting that exports and imports represent a significant portion of Russia's gross domestic product (about 30\% in both constant and current prices for the period from 1995 to 2020 for exports and about $25 \%$ for imports), therefore, accurate forecasts of trade volumes are useful for GDP forecasting.

A large body of research on modelling the dynamics of export and import volumes is available. In case of imports, a classical approach is to estimate the import demand function, while the supply of imports is assumed perfectly elastic. For example, Clarida (1996) and Senhadji (1998) derive long-term correlations from theoretical models, according to which aggregate imports are co-integrated with an indicator of aggregate expenditure and an indicator of relative prices of imported and domestic goods. Estimating the export demand function is more difficult, as demand comes from many countries simultaneously. Senhadji (1999) proposes a model according to which export volumes depend on relative prices for domestic exports and competing goods from other countries, and total output, excluding the exports of countries that are trade partners. Similar approaches to modelling exports and imports using Russian data are described in Yemelyanov (2007).

Moreover, estimating import and export demand functions for each commodity group is too extensive a task that is often hampered by the lack of data. In Russia, the import volumes in USD and in constant prices have almost identical dynamics, which is not the case for exports. It means that the same variables as in the theoretical import demand function in constant prices (the domestic income

\footnotetext{
2 The first six digits of FEACN codes are identical with codes of the international Harmonised System.

${ }^{3}$ Nowcasting is a short-term forecast for the economic indicator in a current period for which official statistics are still unavailable.
} 
indicator and the real exchange rate) can be used as regressors to specify the import demand function and forecast import volumes.

In addition, estimating the demand functions (for both exports and imports) involves the unbiased estimate of elasticity parameters for income and relative prices. The demand function can be seen as a cointegration ralationship. If a cointegration is present, an Error Correction Model (ECM) is built up, otherwise Vector Autoregression (VAR) is used. In both cases, the model is specified using only the past values of the indicators considered. Such a model will make an inherently worse forecast than a model that involves contemporary predictors. However, the inclusion of contemporary variables may entail endogeneity and requires tools for the unbiased estimate of parameters. As Polbin and Fokin (2020) show in their paper on estimating the Russian import demand function, the unbiased estimate of parameters is not necessary for a high-quality forecasting. The authors conclude that the best-quality import nowcast is obtained using a model that includes the current real exchange rate and estimating the model by means of the Ordinary Least Square method (OLS). A model estimated using the Generalised Method of Moments (GMM) as well as a model including only lagged values produces worse forecasts.

In our view, the development of approaches to forecasting Russia's exports and imports specifically has not received sufficient attention in the literature. Only periodic reviews of the current economic situation in Russia and macroeconomic forecasts by the Bank of Russia, the Ministry of Economic Development and the Gaidar Institute ${ }^{4}$ are available, which are based on various structural models as well as standard Autoregressive Integrated Moving Average (ARIMA) and VAR models. In this paper, we propose models for forecasting not only the aggregate series of value exports and imports, but also trade volumes for the separate commodity groups. For example, the Bank of Russia provides data on exports of crude oil, petroleum products, natural gas, and liquefied natural gas in addition to data on aggregate exports in the analytical presentation of the balance of payments estimates. We also consider a whole set of alternative forecasting methods not previously applied, as far as we know, to foreign trade indicators, as well as a different approach to the selection of potentially important predictors for the variables in question.

To reach our goal, we use machine learning models and Bayesian econometrics models that are not subject to the curse of dimensionality, namely: Elastic Net (EN), Random Forest (RF), XGBoost (XGB), Stochastic Search Variable Selection (SSVS), Autoregression (AR) of the first order with the Least Absolute Shrinkage and Selection Operator (LASSO) - AR-LASSO. We also calculate a weighted average of the forecasts obtained with the help of machine learning methods (EN, RF, XGB), with weights in inverse proportion to errors in a validation sample.

\footnotetext{
${ }^{4}$ See, for example, Bank of Russia (2020), Ministry of Economic Development of the Russian Federation (2020), Gaidar Institute and RANEPA (2020).
} 
The set of models used is based on two principles. First, the model should not be subject to the curse of dimensionality, i.e. be able in one way or another to select only those regressors that have the greatest explanatory power from a large data set. Second, the model should work well enough compared to classical methods considered in the earlier studies on macroeconomic indicator forecasting.

For example, Jokubaitis et al. (2021) use the LASSO model and its modifications to get a sparse matrix from the whole dataset for nowcasting and forecasting quarterly GDP and its components in the USA and some euro zone countries. According to their work, the LASSO method provides better forecasts in most cases compared to the ARIMA benchmark model.

The Dynamic Factor Model (DFM) and its modifications can be applied to extract useful information from a large number of predictors. Li and Chen (2014) compare LASSO and EN predictive capabilities with those of DFM for twenty macroeconomic variables, such as inflation, employment, money supply, the exchange rate, etc. For the majority of variables under consideration, the LASSO and EN models surpass DFM in the quality of forecasting, and the combination of forecasts derived from these models helps reduce the Mean Square Forecast Error (MSFE) even more.

Ensemble methods - RF and Boosting - perform well enough in Gareev (2020), forecasting the growth rate of quarterly gross fixed capital formation in Russia, surpassing, in the quality of forecasting, not only simple Autoregression and Random Walk, but also regularisation methods such as LASSO and its modifications, Ridge, EN and Spike, and Slab Bayesian method. Baybuza (2018) obtain similar results, by applying machine learning techniques to forecast inflation in Russia, showing that the RF and Boosting model forecast inflation just as well as more traditional models.

The idea to apply SSVS based on our data comes from Koop (2013), who tests Bayesian methods with various prior distributions for VARs of several sizes and compares forecasts of GDP, consumer price index, and interest rate (federal funds rate). The author demonstrates that Bayesian VARs forecast better compared to factor methods for each dependent variable over any horizon.

The FCS data we are looking at is released with a lag in relation to statistics on the commodity prices, the real effective exchange rate, and other indicators in question. That is why it is possible to build a nowcast in real time based on the models under consideration, that is, to estimate the dynamics of the trade indicators in the current quarter, when the official data on the right-hand side regressors is known, but the data on the forecast variable have not yet been published. We test the quality of pseudo-out-of-sample nowcasts to select the best forecasting model. In the final part of our work, we compare the quality of nowcasts of the models we apply with the Bank of Russia nowcasts for the period from 2019Q3 to 2020Q4. 


\section{The models applied}

\subsection{Elastic Net (EN)}

For forecasting under the curse of dimensionality, one of the most popular solutions is, perhaps, to build a model with regularisation. The EN model (Zou and Hastie, 2005) combines the two basic LASSO and Ridge regularisations (Tibshirani, 1996). This model uses the OLS functionality for linear regression with an additional term penalising coefficients for their excessive value.

$\underset{\beta}{\arg \min } \frac{1}{n} \sum_{i=1}^{n}\left(y_{i}-\beta_{0}-\sum_{j=1}^{p} \beta_{j} x_{i j}\right)^{2}+\lambda\left(\alpha \sum_{j=1}^{p}\left|\beta_{j}\right|+(1-\alpha) \sum_{j=1}^{p} \beta_{j}^{2}\right)$,

where $y_{i}$ is the explained variable, $i=1, \ldots, n ; x_{i j}-j$-th explanatory variable with $j=1, \ldots, p ; \beta_{j}$ is the coefficient before the $j$-th explanatory variable; $\lambda$ is the hyperparameter responsible for the penalty strength; $\alpha$ is the hyperparameter responsible for the L1- and L2-regularisation weight. Parameter $\lambda$ is responsible for the force with which the coefficients will be pulled down to zero.

According to Zou and Hastie (2005), simulations provide better efficiency of Ridge forecasting compared to LAASO when $n>p$ and predictors are highly correlated. The authors also demonstrate that L1-regularisation by parameters can nullify the coefficients for the variables with low explanatory power. The output, therefore, is a sparse vector of coefficient estimates - a solution for the problem of selecting relevant regressors.

When building EN model, a necessary procedure is to normalise the explanatory variables. Since coefficients are penalised for their absolute value with the same weight $\lambda$, it is necessary to avoid the variables with different variances.

\subsection{Random Forest (RF) and Gradient Boosting (XGBoost)}

$\mathrm{RF}$ is based on the decision tree algorithm. At each stage, the optimal splitting of the whole sample $R$ is defined based on $N$ observations by any feature $x_{j}$ and the threshold value $t$ for this feature, setting the condition for the splitting of the top point: $R_{l}(j, t)=\left\{x \mid x_{j}<t\right\}, R_{r}(j, t)=\left\{x \mid x_{j} \geq t\right\}$, according to the quality functional $Q(R, j, t)$. Observations for which the condition is met, go into the left-hand subsample $R_{l}$ (of $N_{l}$ observations), and the rest - to the right-hand subsample $R_{r}$ (of $N_{r}$ observations). The quality functional for this algorithm is described as follows:

$$
Q(R, j, t)=H(R)-\frac{N_{l}}{N} H\left(R_{l}\right)-\frac{N_{r}}{N} H\left(R_{r}\right),
$$

where $H(R)$ is a certain measure of the sample homogeneity.

For regressions, the information value of the top point is measured using the variance of the target variable values in it - the less they differ from each other, the more information we obtain. 
The task is to maximise $Q(R, j, t)$ while minimising $H\left(R_{l}\right)$ and $H\left(R_{r}\right)$, that is, at each step a condition is sought to split the sample $R$ so that, upon splitting, the scattering of the values of the explanatory variable in the left and right subsamples are minimal. The lowest nodes ('leaves') of the tree, which the algorithm no longer splits, contain the algorithm's response. For regressions, the solution is the mean value of the target variable for observations included in these tops.

If no stopping criterion is specified, the splitting process will continue until the tree reaches the maximum depth. The tree would perform perfectly on a training sample, but will show poor results on new data, that is, it will be overtrained. For this purpose, ensemble methods have been developed, i.e. a learning technique where not just one model, but a set of models is used. RF is an ensemble over the decision tree: for each tree, a subsample is generated from all the input data, and the number of regressors to train the model is selected randomly from the whole set (Breiman, 2001). The final forecast for the regression is the average of the forecasts of each of the decision trees.

Trees in RF are trained independently. Gradient boosting and, then, its upgrade XGBoost, have been proposed to build a model encompassing the results of previous iterations (Chen and Guestrin, 2016).

Let us consider an optimisation boosting task for decision trees, based on which a decision tree is selected at the step $t$ :

$$
\mathcal{L}^{(t)}=\underset{f_{t}\left(x_{i}\right)}{\arg \min } \sum_{i=1}^{n} l\left(y_{i}, \hat{y}_{i}^{(t)}\right)+\Omega\left(f_{t}\right),
$$

where $f_{t}$ is the function (a decision tree in our case) whose optimum value we search for at step $t$; $x_{i}$ is a set of features of the $i$-th observation of the learning sample; $y_{i}$ is an actual value of the $i$-th observation of the training sample; $\hat{y}_{i}^{(t)}$ is the sum total of predicted deviations of the first $t$ trees; $l$ is the loss function; $\Omega\left(f_{t}\right)$ is a regularisation function penalising the tree for excessive complexity and impeding its overtraining.

Various specifications could be considered as a regularisation function. The universal function is as follows:

$$
\Omega\left(f_{t}\right)=\gamma T+\frac{1}{2} \lambda \sum_{j=1}^{T} w_{j}^{2},
$$

where $T$ is the number of leaves in the tree, $w$ is the forecast values in the leaves, and $\lambda, \gamma$ are the regularisation parameters. The inclusion of this function into the target functional prevents unnecessary tree complexity and also penalises for the value of the forecasts in the leaves, which reflects the weight of the tree forecast in the ensemble.

An additive strategy for model training is used in the boosting. The forecast of each next step takes into account the algorithm's response at the previous step: 


$$
\hat{y}_{i}^{(t)}=\sum_{k=1}^{t} f_{k}\left(x_{i}\right)=\hat{y}_{i}^{(t-1)}+f_{t}\left(x_{i}\right) .
$$

Let us write the optimisation problem using the Mean Squared Error (MSE) as the loss function $l$ and inserting $\hat{y}_{i}^{(t)}$ :

$$
\mathcal{L}^{(t)}=\underset{f_{t}\left(x_{i}\right)}{\arg \min } \sum_{i=1}^{n}\left(f_{t}\left(x_{i}\right)-\left(y_{i}-\hat{y}_{i}^{(t-1)}\right)\right)^{2}+\Omega\left(f_{t}\right) .
$$

Thus, at the step $t$, the task is to find a tree $f_{t}\left(x_{i}\right)$ that would minimise the functional $\mathcal{L}^{(t)}$ accounting for the residuals, that is, the deviation of the predicted value from the real value derived based on the previous trees. Each next model will strive to correct, as best as possible, the errors of the earlier models.

\subsection{Stochastic Search Variable Selection (SSVS)}

The SSVS is a Bayesian method with a hierarchical prior distribution producing, like LASSO, a sparse vector of regressors with the greatest explanatory potential from a large set of regressors (George and McCulloch, 1993), which is a particularly important factor for our variables selection task under the curse of dimensionality. We consider a linear model where the coefficient at the $j$-th regressor $\beta_{j}$ a priori has a weighted distribution of two normal distributions with zero means, but with strongly different variances. One of the distributions has a small variance with a large density of zero (the coefficient is likely to be equal to zero and this regressor can be excluded from the model), and the other has a greater variance (the coefficient is highly likely to be different from zero, hence the variable should remain in the model).

$$
P\left(\beta_{j} \mid \gamma_{j}\right)=\left(1-\gamma_{j}\right) N\left(0, r_{0 j}^{2}\right)+\gamma_{j} N\left(0, r_{1 j}^{2}\right),
$$

where $\gamma_{j}$ is a random variable with a Bernoulli distribution:

$$
\begin{gathered}
P\left(\gamma_{j}=1\right)=q_{j}, \\
P\left(\gamma_{j}=0\right)=1-q_{j} .
\end{gathered}
$$

We assume $q_{j}$ equal to 0.5 for each $j$, i.e. that each coefficient can $a$ priori be both included in or excluded from the model with equal probability. Following Koop (2013), as $r_{0 j}^{2}$ and $r_{1 j}^{2}$ variances we take the variances of the dual regression coefficient of the explanatory variable for the $j$-th regressor multiplied by 0.1 and by 10 , accordingly.

\subsection{Combined models}

Apart from the basic ARIMA model, whose order is selected based on the Bayesian Information Criterion (BIC), we build an AR-LASSO model following the approach described in Baybuza (2018). At the first stage, we select exogenous factors 
with the help of the LASSO model and then add the first lag of the dependent variable to the explanatory variables. This results in a combined LASSO and AR(1)-model.

In addition, to enhance the nowcast quality, we calculate a Weighted Model (WM) nowcast as a weighted average from the forecasts derived with the help of the EN, RF, and XGB machine learning methods. As each model weight we use the ratio of the Root Mean Squared Error (RMSE) of this model's nowcasts in a validation sample to the sum total of the inverse RMSE of all three models.

\section{Description of the data and the hyperparameter selection procedure}

\subsection{Data applied}

For the purpose of the research, we have constructed a large dateset of the dollar volumes of Russian exports and imports for the period from 2005Q1 to 2020Q4 by two-digit commodity groups under the FEACN classification, reported by the FCS. In total, we have statistics on 97 commodity groups as well as on aggregate exports and imports. The aggregated commodity category groups are provided in Table $1 .^{5}$

Table 1. Export and import categories

\begin{tabular}{ll}
\hline Aggregate groups & FEACN codes \\
\hline Total exports and imports & - \\
\hline Food products and agricultural raw materials (textile raw materials excluded) & $01-24$ \\
\hline Mineral products, fuel and energy products & $25-27$ \\
\hline Chemical products, rubber & $28-40$ \\
\hline Hides, furs, and articles made therefrom & $41-43$ \\
\hline Wood, pulp, and paper products & $44-49$ \\
\hline Textile, textile products, and footwear & $50-67$ \\
\hline Precious stones, precious metals, and articles made therefrom & 71 \\
\hline Metals and articles made therefrom & $72-83$ \\
\hline Machinery, equipment, and vehicles & $84-90$ \\
\hline Other goods & $68-70 ; 91-97$
\end{tabular}

Note: Export commodity group under code 50 (silk) has been excluded due to a large number of missing values at the specified interval. Commodity group under code 77 is in reserve and not used.

Source: compiled by the authors

The following components are included as predictors: the first lags of export and import volume growth rates across all commodity groups, current and first lags of growth rates of the real effective exchange rate, the industrial production index, the current and first lags of various commodity prices with the largest share in aggregate exports and imports (oil, gas, gasoline, wood, wheat, non-ferrous metals, copper, aluminium, steel, gold, grain, organic chemical products, medical

\footnotetext{
${ }^{5}$ See a more detailed breakdown by commodity groups in the Russian Customs Statistics of Foreign Trade newsletter, Russian Export and Import by Commodity Groups across All Countries table (in Russian), http://stat.customs.ru/documents (accessed on 21 July 2021).
} 
equipment and supplies, meat and vegetable products, etc.) as well as forwardlooking indicators of economic activity published by the OECD - the Composite Leading Indicator (CLI), the Business Confidence Index (BCI), and the Consumer Confidence Index (CCI) for Russia, the USA, China, the ECD, European OECD member states, the G7, and the eurozone. Thus, the entire explanatory variable space for each dependent variable is 273 regressors $^{6}$ with 60 observations.

The series of export and import volumes as well as all the explanatory variables, except for the CLI, BCI, CCI indices (these indices are indicators cleared of the long-term trend), are taken at the growth rates, quarter-on-quarter of the previous year. This procedure accounts for the seasonal components while still maintaining the original series. As we know, seasonal adjustment involves working with an artificial time series, and on samples of the length $T$ and the length $T+1$ this procedure can give very different values of the adjusted series at the time $T$. An additional description of the variables can be found in the Appendix, Table A1 (see online version of the paper).

Due to the specifics of the statistics release dates, we can build a nowcast of volume growth rates. Current commodity exchange prices, the real exchange rate and indices become available in the second week of the month following the reporting one, and FCS quarterly bulletins 'Customs Statistics of Foreign Trade of the Russian Federation' are published with a lag of two quarters: for example, the FCS bulletin for 2020Q4 was published in 2021Q2. On roughly the 10th day of each month, the FCS publishes more recent data, ${ }^{7}$ with a lag of two months rather than two quarters: for example, data for April 2021 became available in June 2021; but their disadvantage as a source is the lack of historical data (only the last three years are available in the relevant section on the FCS website). Therefore, we choose the first of these sources for analysis - the FCS quarterly bulletins, which have been available since 2005, but are issued with a two quarters delay. Thus, the nowcast built is one month ahead of the official statistics.

\subsection{Selection of hyperparameters}

For a number of models selected, the question arises as to which hyperparameters are optimal. In practice, cross validation is often used to determine the best values of hyperparameters (in terms of the quality of pseudo-out-of-sample forecasts), where the parameter is selected on a deferred sample.

The classical grid search is used for searching and optimising hyperparameters. Since our data are time series, we perform cross validation with an expanding window, which does not require mixing the data, and does not lead to a loss of extracted information. The method consists of the division of the whole sample

\footnotetext{
6 The first lags of total exports and imports, 95 export commodity groups (excluding groups 50 and 77), 96 import commodity groups (excluding group 77), as well as current and first lags of 40 exogenous predictors.

${ }^{7}$ See http://stat.customs.gov.ru/analysis (in Russian, accessed on 21 July 2021).
} 
into three parts. In this work, following Nicholson et al. (2017), equal parts at $1 / 3$ of the sample are used. In the first part, the model is trained with various set values of hyperparameters. Then, each previously trained model builds a pseudoreal nowcast one point ahead. The forecast is stored, and the value is added to the training sample, after which the models are re-estimated and a forecast is made for the next point, and so on until the deferred sample is exhausted. Having obtained vectors from the forecasts built by models with different values of hyperparameters, we compare the models by the quality of the forecast using RMSE. Then the best model is trained on the first and second parts, and similarly to the algorithm described earlier, a pseudo-real nowcast is built on the third part. It is based on the results of the forecast quality in the last part that all the models built in this work are compared with each other.

In the case of EN, the question arises as to which $\alpha$ and $\lambda$ are optimal, with what weight each of the models should be included and what penalty should be used for the coefficients. When building the RF, the important hyperparameters for selection are the minimum number of observations at the final top nodes (leaves), the maximum number of features by which a split is searched for at each top node, and the minimum number of observations required to split the inner leaf. As to the number of trees in each forest, an important empirical fact is that the $\mathrm{RF}$ is not inclined to overtraining, that is, with an increase in the number of trees, the quality on the deferred sample first increases, and then approaches the asymptote. Since the asymptote is approached at different rates, in this paper, when building the RF for each dependent variable, we took 1,000 decision trees.

In contrast to the RF where trees are trained independently and, as a result, there is no improvement in quality from a certain moment, the number of trees in $\mathrm{XGB}$ is an important hyperparameter, since each subsequent tree adapts to the already available composition of trees, taking into account the errors of previous iterations. Therefore, for XGB, the parameters such as the number of decision trees, the maximum depth of each tree, the number of features on which each tree is built, as well as the values of the regularisation coefficients responsible for the penalty effect for the complexity of the tree are determined on a deferred sample. ${ }^{8}$

\section{Comparison of the predictive power of the models}

We compare pseudo-out-of-sample nowcasts built by the models selected for each commodity group with the ARIMA benchmark without exogenous variables, the order of which is selected based on BIC, using RMSE as a quality metric. The test sample includes the period from 2015Q1 to 2020Q4. The results of the comparison (the percentage of the total number of categories where the considered model is better than ARIMA) are shown in Table 2.

\footnotetext{
${ }^{8}$ The sets that we used to find optimum hyperparameters for each model are given in the Appendix (see Table A2).
} 
Table 2. Comparison of models with ARIMA by forecast quality

\begin{tabular}{llllllllll}
\multicolumn{8}{c}{ The model is better than ARIMA (in \% of cases) } \\
& EN & RF & XGB & WM & SSVS & AR-Lasso & At least one model \\
\hline Among the export categories & 53 & 52 & 42 & 69 & 12 & 31 & 84 \\
\hline Among the import categories & 41 & 51 & 35 & 58 & 5 & 26 & 70 \\
\hline Among all categories & 47 & 51 & 38 & 64 & 8 & 28 & 76 \\
\hline
\end{tabular}

Source: author's calculations

$\mathrm{WM}, \mathrm{EN}$, and RF perform better than others in pair-wise comparison with ARIMA. These models predict export volumes more accurately in over a half of the cases. Furthermore, RF predicts import volumes better in $51 \%$ of cases, and WM in $58 \%$ of cases. If we consider the best result of all the six models, the quality of forecasts for the models will be higher than that of ARIMA in 76\% of the cases among all categories. It should be noted that ARIMA proves to better forecast the volumes of imports than those of exports, and often shows the best result for small commodity groups.

The Appendix (see Tables A3 - A4) shows the ratio of the RMSE of all models to the RMSE of ARIMA, as well as the results of the Diebold-Mariano test (Diebold and Mariano, 2002), with a pseudo-out-of-sample nowcast of export and import volumes for the ten largest commodity groups, which cover roughly $85 \%$ of total exports and about $60 \%$ of total imports on average over the period under review.

\section{Comparison with the Bank of Russia's historical forecasts}

In this section, we compare the quality of nowcasts of the total exports and total imports built by machine learning models with the quarterly nowcasts of the Bank of Russia for the period from 2019Q3 to 2020Q4.

The Bank of Russia regularly publishes analytical comments on the balance of payments of Russia, ${ }^{9}$ which contain tables with the total actual USD values of exports and imports, as well as their estimates for the current quarter. On the last page of the comment, the data cut-off date is indicated. When building a nowcast based on machine learning models, we use the same data cut-off date as in the comment. According to the methodological notes to the assessment of the balance of payments, the Bank of Russia's assessments rely on recent monthly data of the FCS and the dynamics of other indicators. In other words, when the nowcast for the current quarter is built, data for the first two months of this quarter is used. In our models this approach is not feasible due to the lack of monthly historical data of the FCS (they are available only for the last three years at any moment of time). Besides, the Bank of Russia faces the challenge of regular data revision by the FCS, and we are building a retrospective forecast on the already revised data. Despite these two factors, in general, the initial conditions for building the forecast are comparable.

\footnotetext{
${ }^{9}$ See the Balance of Payments of the Russian Federation, https://cbr.ru/eng/analytics/dkp/bal/ (accessed on 21 July 2021).
} 
For comparison, we have selected three models for forecasting exports and imports, which showed the best quality in the validation sample. The quality is compared on the validation sample, since the test sample contains a comparison period (2019Q3 - 2020Q4). The results of the comparison are shown in Figures 1 and 2.

Figure 1. Deviation of the actual import volume from the forecast, $\$$ billion

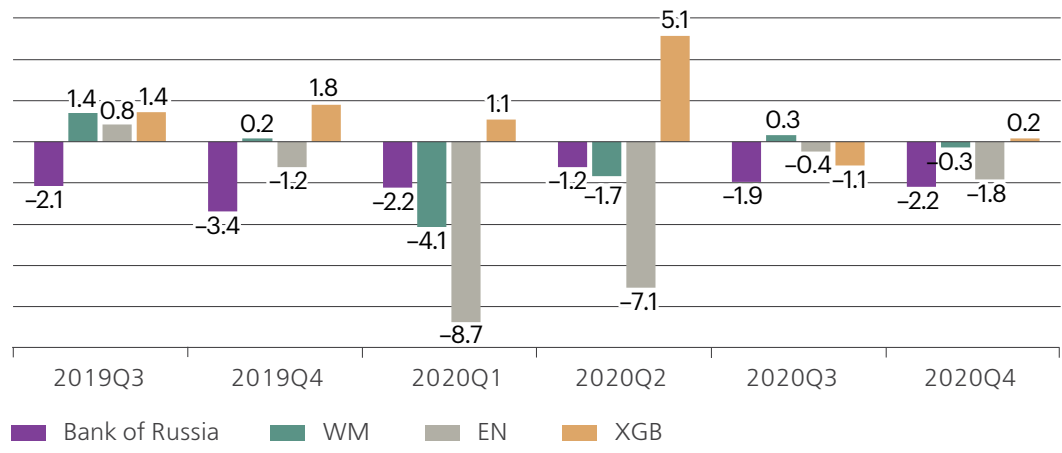

Source: author's calculations

Figure 2. Deviation of the actual export volume from the forecast, $\$$ billion

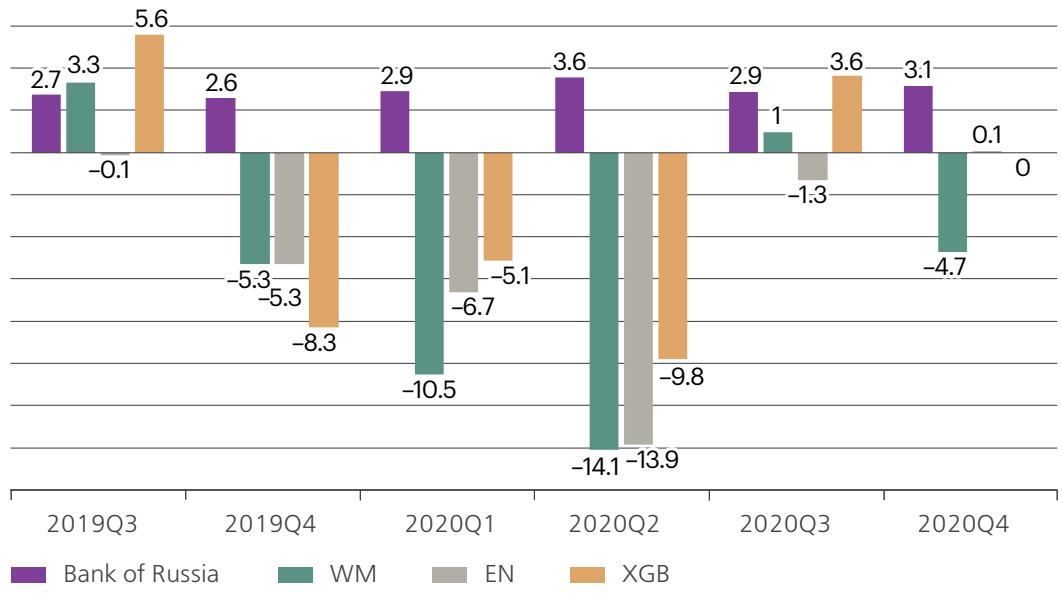

Source: author's calculations

Table 3 shows the results of calculating various quality metrics ${ }^{10}$ of the nowcasts built by our models and the nowcasts of the Bank of Russia: RMSE, Mean Absolute Error (MAE), Mean Absolute Percentage Error (MAPE), and Percentage Mean Absolute Deviation (PMAD). The best results in the row for each indicator are in bold. It should be noted that when forecasting exports, the Bank of Russia's nowcast turned out to be of higher quality for all metrics, while the nowcast built by a weighted model turned out to be the best for imports for all metrics.

\footnotetext{
${ }^{10}$ See formulas in the Appendix, Table A5.
} 
Table 3. Comparison of the quality of the nowcast using various metrics

\begin{tabular}{|c|c|c|c|c|c|c|c|c|}
\hline \multirow[t]{2}{*}{ Metric } & \multicolumn{4}{|c|}{ Export } & \multicolumn{4}{|c|}{ Import } \\
\hline & Bank of Russia & WM & RF & XGB & Bank of Russia & WM & EN & XGB \\
\hline RMSE & 7.3 & 19.4 & 16.3 & 15.34 & 5.6 & 4.7 & 11.5 & 5.8 \\
\hline MAE & 17.8 & 49.3 & 27.3 & 32.4 & 13.1 & 8.0 & 20.1 & 10.7 \\
\hline MAPE & $20.0 \%$ & $45.4 \%$ & $33.2 \%$ & $36.6 \%$ & $21.4 \%$ & $14.3 \%$ & $36.4 \%$ & $19.0 \%$ \\
\hline PMAD & $3.2 \%$ & $8.9 \%$ & $4.9 \%$ & $5.6 \%$ & $3.6 \%$ & $2.2 \%$ & $5.6 \%$ & $3.0 \%$ \\
\hline
\end{tabular}

Source: author's calculations

Table 4. Frequency of selection of exogenous predictors by the Random Forest model, \%

\begin{tabular}{l|lll} 
Predictor & $\begin{array}{l}\text { Frequency of selection } \\
\text { of this predictor among } \\
\text { export commodity groups }\end{array}$ & Predictor & $\begin{array}{l}\text { Frequency of selection } \\
\text { of this predictor among } \\
\text { import commodity groups }\end{array}$ \\
\hline $\begin{array}{l}\text { Global Price Index } \\
\text { of All Commodities }\end{array}$ & 35 & $\begin{array}{l}\text { Global Price Index of All } \\
\text { Commodities }\end{array}$ & 57 \\
\hline CCI for Russia & 26 & $\begin{array}{l}\text { Brent crude oil price - } \\
\text { Europe }\end{array}$ & 50 \\
\hline $\begin{array}{l}\text { Brent crude oil price }- \\
\text { Europe }\end{array}$ & 25 & Global price of corn & 35 \\
\hline $\begin{array}{l}\text { Producer price index: } \\
\text { basic organic chemical } \\
\text { manufacturing }\end{array}$ & 21 & $\begin{array}{l}\text { Real Effective Exchange } \\
\text { Rate for Russia }\end{array}$ & 35 \\
\hline $\begin{array}{l}\text { Producer price index: } \\
\text { wood pulp }\end{array}$ & 15 & CCI for Russia & 34 \\
\hline
\end{tabular}

Source: author's calculations

An interesting question is which predictors are the most important ones for forecasting. Let us consider it on the example of the RF model, which is the best in quality after the weighted model. Since the RF is a collection of decision trees, we can calculate which predictors were effective in building trees and have the greatest impact on the target variable. When building a tree, to split a top into two nodes, a predictor and a threshold value for it are searched for at each step, so that the scatter of the values of the target variable in the left and right nodes is minimal. For regression, MSE is used, that is, the more we managed to reduce the MSE in splitting, the more important the predictor is considered, because it helps split the sample so that the values of the target variable in each node differ from each other the least. For each individual decision tree, we can select the most important predictors by sorting them by how much they reduced the error during the splitting, provided that the error reduction is necessarily weighted by the number of observations in the node. To determine the importance of each predictor in the RF, this procedure is performed for each tree, and the average result is taken.

As can be seen from the data contained in Table 4, the most important predictor is the Global Price Index of All Commodities: the model selects it for 35\% of export categories and for $57 \%$ of import commodity groups. Furthermore, the oil price and the CCI for Russia published by the OECD play an important role in both cases. For imports, the real exchange rate is also an important variable, which corresponds to theoretical concepts. 


\title{
6. Conclusion
}

This paper tests popular models for working under the curse of dimensionality for the purpose of nowcasting and forecasting the growth rates of the quarterly dollar value volumes of Russian exports and imports across commodity groups. The weighted model of machine learning methods shows the highest quality of forecasts. In terms of RMSE it surpasses the benchmark ARIMA model forecasts for $69 \%$ of export commodity groups and $58 \%$ of import commodity groups. For aggregated exports and imports, mineral fuel exports (commodity group 27), and a number of other commodity groups, the model manages to obtain statistically significantly better forecasts, according to the Diebold-Mariano test.

The models we test give quite similar forecasts to those of the Bank of Russia under comparable conditions. In the interval from 2019Q3 to 2020Q4, the weighted model of machine learning methods shows a higher accuracy of total import nowcasting compared to the forecasts made by the Bank of Russia. The most relevant predictors in the RF model are consistent with theoretical concepts: the most frequently chosen indicator is the Global Price Index of All Commodities.

\author{
Appendix is available at \\ http://rjmf.econs.online/en; \\ doi.org/10.31477/rjmf.202103.34
}

\section{References}

Bank of Russia (2020). Bank of Russia's Medium-Term Forecast Following the Bank of Russia Board of Directors' Key Rate Meeting on 24 July 2020. https://www.cbr.ru/ collection/collection/file/28035/forecast_200724_e.pdf [accessed on 21 July 2021].

Baybuza, I. (2018). Inflation Forecasting Using Machine Learning Methods. Russian Journal of Money and Finance, 77(4), pp. 42-59. https://doi.org/10.31477/rjmf201804.42

Breiman, L. (2001). Random Forests. Machine Learning, 45(1), pp. 5-32. https://doi.org/10.1023/A:1010933404324

Chen, T. G. and Guestrin, C. (2016). XGBoost: A Scalable Tree Boosting System. In: Proceedings of the 22nd ACM SIGKDD International Conference on Knowledge Discovery and Data Mining. New York: Association for Computing Machinery, pp. 785-794. https://doi.org/10.1145/2939672.2939785

Clarida, R. H. (1996). Consumption, Import Prices, and the Demand for Imported Consumer Durables: A Structural Econometric Investigation. The Review of Economics and Statistics, 78(3), pp. 369-374. https://doi.org/10.2307/2109783

Diebold, F. X. and Mariano, R. S. (2002). Comparing Predictive Accuracy. Journal of Business and Economic Statistics, 20(1), pp. 134-144. https://doi.org/10.1198/073500102753410444

Gaidar Institute and RANEPA (2020). Monitoring ekonomicheskoy situatsii v Rossii: tendentsii i vyzovy sotsial'no-ekonomicheskogo razvitiya [Monitoring of Russia's 
Economic Outlook. Trends and Challenges of Socio-Economic Development], 10. [In Russian]. http://www.iep.ru/files/text/crisis_monitoring/2020_10-112_April.pdf [accessed on 21 July 2021].

Gareev, M. (2020). Use of Machine Learning Methods to Forecast Investment in Russia. Russian Journal of Money and Finance, 79(1), pp. 33-56. https://doi.org/10.31477/rjmf.202001.35

George, E. I. and McCulloch, R. E. (1993). Variable Selection via Gibbs Sampling. Journal of the American Statistical Association, 88(423), pp. 881-889. https://doi.org/10.1080/01621459.1993.10476353

Jokubaitis, S., Celov, D. and Leipus, R. (2021). Sparse Structures with LASSO through Principal Components: Forecasting GDP Components in the Short-Run. International Journal of Forecasting, 37(2), pp. 759-776. https://doi.org/10.1016/j.ijforecast.2020.09.005

Koop, G. M. (2013). Forecasting with Medium and Large Bayesian VARs. Journal of Applied Econometrics, 28(2), pp. 177-203. https://doi.org/10.1002/jae.1270

Li, J. and Chen, W. (2014) Forecasting Macroeconomic Time Series: LASSO-Based Approaches and their Forecast Combinations with Dynamic Factor Models. International Journal of Forecasting, 30(4), pp. 996-1015. https://doi.org/10.1016/j.ijforecast.2014.03.016

Ministry of Economic Development of the Russian Federation (2020). Prognoz sotsial'noekonomicheskogo razvitiya Rossiyskoy Federatsii na 2021 god i na planovyy period 2022 i 2023 godov [Medium-Term Forecast of the Socio-Economic Development of the Russian Federation]. [In Russian]. https://www.economy.gov.ru/material/file/956cde63 8e96c25da7d978fe3424ad87/Prognoz.pdf [accessed on 21 July 2021].

Nicholson, W. B., Matteson, D. S. and Bien, J. (2017). VARX-L: Structured Regularization for Large Vector Autoregressions with Exogenous Variables. International Journal of Forecasting, 33(3), pp. 627-651. https://doi.org/10.1016/j.ijforecast.2017.01.003

Polbin, A. and Fokin, N. (2020). Modeling the Dynamics of Import in the Russian Federation Using the Error Correction Model. Applied Econometrics, 59, pp. 88-112. [In Russian]. http://pe.cemi.rssi.ru/pe_2020_59_088-112.pdf [accessed on 21 July 2021].

Senhadji, A. (1998). Time-Series Estimation of Structural Import Demand Equations: A Cross-Country Analysis. IMF Staff Papers, 45(2), pp. 236-268.

Senhadji, A. (1999). Time Series Analysis of Export Demand Equations: A Cross-Country Analysis. IMF Staff Papers, 46(3), pp. 259-273.

Tibshirani, R. (1996). Regression Shrinkage and Selection Via the Lasso. Journal of the Royal Statistical Society: Series B (Methodological), 58(1), pp. 267-288. https://doi.org/10.1111/j.2517-6161.1996.tb02080.x

Yemelyanov, S. S. (2007). Modelirovanie eksporta i importa Rossijskoj Federacii v sisteme prognozno-analiticheskih raschetov [Modeling of Export and Import of the Russian Federation in the System of Forecasting and Analytical Calculations]. Problemy prognozirovaniya (Studies on Russian Economic Development), 2, pp. 116-126. [In Russian]. https://ecfor.ru/publication/modelirovanie-eksporta-i-importa-rossijskojfederatsii/ [accessed on 21 July 2021].

Zou, H. and Hastie, T. (2005). Regularization and Variable Selection Via the Elastic Net. Journal of the Royal Statistical Society: Series B (Statistical Methodology), 67(2), pp. 301-320. https://doi.org/10.1111/j.1467-9868.2005.00503.x 